\section{Angle-closure glaucoma in East Asian and European people. Different diseases?}

\begin{abstract}
In contrast to the pattern of disease in Europeans, primary angle closure has a higher prevalence and tends to be asymptomatic in East Asians. The higher prevalence is attributed to differences in anterior chamber and angle anatomy. Several studies suggest that central anterior chamber depth is shallower in East Asians than in Europeans, although this is not universally accepted. It is debated whether pupil block is the predominant mechanism of angle closure in Asian people. Meaningful comparison between studies is currently hindered by differences in patient selection, examination technique, and case definition; however, the major scientific deficiency is the paucity of prospective followup data to give an insight into natural history of the disease. This review examines the data on prevalence, risk factors, and mechanism of angle closure. Special consideration is given to limitations of methodology in research to date, with the intention of developing more robust data in future studies.
\end{abstract}

Eye (2006) 20, 3-12. doi:10.1038/sj.eye.6701797; published online 21 January 2005

Keywords: primary angle-closure glaucoma; primary angle closure; anterior chamber; mechanism; pupil block; plateau iris configuration; iridotomy

\section{Introduction}

Several population-based studies have suggested that the prevalence of primary angle closure (PAC) is higher in East Asians than Europeans and Africans. ${ }^{1,2}$ The majority of PAC in Asia tends to be chronic, asymptomatic

$\mathrm{M} \mathrm{He}^{1,2}$, PJ Foster ${ }^{2,3}$, GJ Johnson ${ }^{2}$ and PT Khaw ${ }^{2,3}$

disease. $^{3-7}$ The aetiology of PAC in East Asians, and particularly how anterior segment configuration influences mechanism of angle closure, is not fully understood. This article intends to review the available data and identify priority areas for future research. Particular consideration is given to the limitations of methodology in research to date, with the intention of developing more robust study protocols for future studies.

\section{Definition and classification}

Primary angle-closure glaucoma (PACG) has traditionally been divided into at least four clinical types: acute, subacute/intermittent, chronic and latent, based on the gonioscopic features of the drainage angle, intraocular pressure (IOP), and symptomatology. 8

However, symptoms appear not to be a good indicator of glaucomatous visual loss: $60-75 \%$ of persons suffering an acute episode of PAC recover without optic disc or visual field damage, at least in the short term.,10 The majority of Asian people suffering from angleclosure experience no symptoms. ${ }^{3,4}$ This method of classification is increasingly being seen as inadequate for both clinical and research purposes.

There is a growing trend to adopt a uniform definition of glaucoma, synonymous with glaucomatous optic neuropathy (GON) resulting from different mechanisms of disease: open-angle, angle-closure, and secondary glaucoma. This was initially intended to standardize the use of the term 'glaucoma' in epidemiological research, as signifying visually significant disease. The use of this convention for angle-closure glaucoma has now been adopted by the American Academy of Ophthalmology ${ }^{11}$ and SEAGIG (The Southeast Asia Glaucoma Interest Group). ${ }^{12}$ Meaningful
'Zhongshan Ophthalmic

Center, Guangzhou,

People's Republic of China

${ }^{2}$ Institute of Ophthalmology, University College London, England

${ }^{3}$ Glaucoma Research Unit, Moorfields Eye Hospital, London, England

Correspondence: PJ Foster, Department of Epidemiology, Institute of Ophthalmology, Bath Street, London EC1V 9EL, England Tel: (44) 207608 6907; Fax: (44) 2072503207.

E-mail:p.foster@ ucl.ac.uk

Received: 16 June 2004 Accepted in revised form: 1 November 2004 Published online: 21 January 2005 
classification of the angle-closure process requires the use of two separate schemes in parallel (Table 1). Firstly, the stage of the angle-closure process should be identified. Three broad categories: suspect, established angleclosure and angle-closure glaucoma follow our conceptual model of the natural history, and reflect prognosis for vision. ${ }^{13-15}$ Within each category, there is a spectrum of severity. Narrower angles are more likely to close than wider angles. ${ }^{16}$ The likelihood of satisfactorily controlling IOP is inversely related to the circumference of trabecular meshwork affected by peripheral anterior synechiae (PAS) ${ }^{17,18}$ Categorizing the stage of disease does not identify the mechanism causing the angle to close. Ritch's classification is currently the most logical for this purpose, dividing the mechanisms responsible for angle closure into four categories, each abnormality having a more posterior location, specifically: pupil block, plateau-iris, lens-induced, and retrolenticular causes. ${ }^{19}$ Our preference is to substitute the term anterior, nonpupil block for plateau iris because we have found that, particularly among Asian people, some cases of angle closure remaining after PI (without posterior causes) do not display the characteristic angulation of the peripheral iris and apposition between apex of the ciliary body and posterior surface of the iris.

By using these the staging and mechanism schemes in parallel, management is guided by understanding why closure occurs, the site and severity of tissue damage, and the prognosis for vision. Table 2 compares the relative emphasis of the traditional and new, recommended methods of classifying angle closure.

\section{Prevalence and incidence}

Sparse data suggest that PAC and PACG are uncommon among European-derived people, with prevalence

Table 1 Parallel classification of stage and mechanism of primary angle closure

\section{Disease staging}

Stage 1: Narrow angle (angle-closure suspect) — an anatomical predisposition to closure.

Stage 2: Angle closure-Partial or total closure of the angle with synechiae and /or raised IOP (height and cumulative circumference of PAS should be recorded). (a) Non-ischaemic (b) ischaemic - with tissue injury such as iris whorling or stromal atrophy, often history of symptoms.

Stage 3: Angle closure with glaucomatous optic neuropathy.

Mechanism of closure

A. Pupil block.

B. Anterior non-pupil block - including plateau iris and peripheral iris crowding.

C. Lens-related.

D. Factors behind the lens.
Table 2 Comparison of traditional vs combined staging and mechanism classification of angle-closure glaucoma

\begin{tabular}{|c|c|c|}
\hline Classification & $\begin{array}{l}\text { Traditional } \\
\text { scheme }\end{array}$ & $\begin{array}{l}\text { Combined 'stage } \mathcal{E} \\
\text { mechanism' scheme }\end{array}$ \\
\hline Nosological basis & Symptoms & $\begin{array}{l}\text { Site-specific tissue damage } \\
\text { and dysfunction } \\
\text { Presumed mechanism } \\
\text { causing closure }\end{array}$ \\
\hline $\begin{array}{l}\text { Specifies visual } \\
\text { dysfunction? }\end{array}$ & No & Yes \\
\hline Indicates prognosis? & No & Yes \\
\hline $\begin{array}{l}\text { Guides targeted } \\
\text { intervention? }\end{array}$ & No & Yes \\
\hline
\end{tabular}

ranging from $0.04 \%$ in the Beaver Dam Study, ${ }^{20} 0.06 \%$ in Melbourne, ${ }^{21} 0.09 \%$ in Wales, ${ }^{22} 0.4 \%$ in Baltimore (Oral communication, from JM Tielsch, $\mathrm{PhD}$ ) to $0.6 \%$ in North Italy. ${ }^{23}$ Again, the differences in diagnostic definition and insufficient power detecting the small prevalence make further comparison difficult.

Data detailing prevalence of PAC and PACG in Asia have increased considerably over the last decade. Table 3 compares studies of prevalence of PAC and PACG in Europeans and East Asians. Studies in Asia, in common with European studies, are of variable quality. Reports from a rural area near Beijing ${ }^{1}$ and from Lhasa ${ }^{24}$ both suffered methodological drawbacks; angle width was estimated by oblique flashlight test, gonioscopy was not performed for all subjects, and diagnostic criteria and methods were not clearly described. Another population study in Taiwan primarily aimed to evaluate screening techniques was compromised by a low participation rate. ${ }^{4}$ A nationwide study of glaucoma prevalence in Japan suggested a much lower rate of PAC in Japanese, less than $1 / 3$ of the rate seen in Chinese people. ${ }^{25}$ In 1995 , our group conducted a population-based study of glaucoma prevalence in Mongolia, ${ }^{3}$ which found a rate of angle closure similar to Hu's survey in Beijing, although the diagnostic criteria differed considerably. In 1997-8, we also carried out a collaborative study of glaucoma prevalence in Chinese Singaporeans in the Tanjong Pagar district of the island. ${ }^{26}$ When age- and genderstandardized, and with identical definitions, the prevalences of angle-closure suspects, angle closure, and PACG were almost identical to that seen in Mongolia. ${ }^{13}$ These prevalence data are broadly consistent with the concept that angle closure is more common in Chinese people than in Europeans. One important issue identified in population surveys has been that only $25-40 \%$ of cases of angle-closure glaucoma cases have signs or a history of symptomatic attacks. This is important in interpreting the figures for incidence of 'acute' angle closure. $^{3-7}$ 
Table 3 Comparison of the published prevalence data on primary angle closure glaucoma in different populations

\begin{tabular}{|c|c|c|c|c|c|c|}
\hline Study location & $\begin{array}{l}N \geqslant 40 \text { years } \\
\quad(\text { response })\end{array}$ & Ratio: $P A C G: P O A G^{\mathrm{a}}$ & $\begin{array}{l}\text { Ratio: symptomatic: } \\
\text { asymptomatic }\end{array}$ & Angle examination ${ }^{\mathrm{b}}$ & Diagnostic definition ${ }^{\mathrm{C}}$ & Prevalence \\
\hline Beijing (1989) ${ }^{1}$ & $3147(96.0 \%)$ & $43: 1$ & $34: 9$ & Flashlight gonioscopy & Angle + IOP or symptoms & $1.37 \%$ \\
\hline $\begin{array}{l}\text { Japan nationwide } \\
(1991)^{20}\end{array}$ & $8126(50.5 \%)$ & $\begin{array}{l}\text { 28:194 (including } \\
150 \text { NTG) }\end{array}$ & $\mathrm{N} / \mathrm{A}$ & Gonioscopy for all & Angle + IOP & $\begin{array}{l}\text { M: 50-69: } 0.17 \% \\
70+: 0.21 \% \\
\text { F: } 50-69: 0.49 \% \\
70+: 0.85 \%\end{array}$ \\
\hline Tibet $(1992)^{19}$ & $1297(92.4 \%)$ & $\mathrm{N} / \mathrm{A}$ & $\mathrm{N} / \mathrm{A}$ & Flashlight gonioscopy & Angle + IOP or symptoms & $\begin{array}{l}0.15 \% \text { (two cases, } \\
\text { all female) }\end{array}$ \\
\hline Taiwan (1996) & $562(10.3 \%)$ & $\mathrm{N} / \mathrm{A}$ & 6:11 & Gonioscopy for all & $\begin{array}{l}\text { Angle }+(\text { IOP or DPPT or } \\
\text { symptom) }\end{array}$ & $3.02 \%$ \\
\hline Mongolia $(1996)^{4}$ & $942(94.2 \%)$ & $14: 5$ & 3:11 & Gonioscopy for all & New ACS/PAC/PACG scheme & $\begin{array}{l}\text { ACS: } 6.4 \%^{\mathrm{d}} \\
\text { PAC: } 2.0 \% \\
\text { PACG: } 0.8 \%\end{array}$ \\
\hline Singapore $(2000)^{21}$ & $1232(71.8 \%)$ & $14: 22$ & $6: 8$ & Gonioscopy for all & New ACS/PAC/PACG scheme & $\begin{array}{l}\text { ACS: } 6.3 \% \\
\text { PAC: } 2.2 \% \\
\text { PACG: } 0.8 \%\end{array}$ \\
\hline Baltimore (1991) & 5308 & & $\mathrm{~N} / \mathrm{A}$ & Not described & $\mathrm{N} / \mathrm{A}$ & $\begin{array}{l}\text { Black: } 0.90 \% \\
\text { White: } 0.40 \%\end{array}$ \\
\hline Italy $(2000)^{18}$ & $4297(73.9 \%)$ & & $\mathrm{N} / \mathrm{A}$ & $\begin{array}{l}\text { Screening followed } \\
\text { by gonioscopy }\end{array}$ & $\begin{array}{l}\text { (Angle }+ \text { symptoms }+ \text { signs }) \\
+(\text { IOP or disc or field })\end{array}$ & $\begin{array}{l}\text { M: } 0.2 \% \\
\text { F: } 0.9 \%\end{array}$ \\
\hline
\end{tabular}

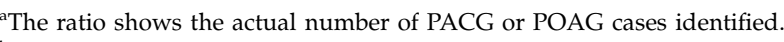

${ }^{\mathrm{b}}$ Angle closure was decided by either gonioscopy for all subjects or screening by oblique flashlight test firstly followed by gonioscopy for definitive diagnosis.

'Angle: anterior chamber angle; IOP: elevated intraocular pressure; Symptoms: previous confirmed symptoms of acute angle-closure; Signs: PAS or other signs of lens injury or ischaemic iris damage; DPPT:

positive dark rooms prone provocative test; Disc: glaucomatous optic neuropathy; Field: glaucomatous visual field damage
${ }^{\mathrm{d}}$ ACS: angle-closure suspect; PAC: primary angle closure; PACG: primary angle-closure glaucoma. The ACS category includes those in PAC and PACG, PAC category includes those in PACG. 
Incidence data are useful in quantifying the amount of symptomatic, 'acute' angle closure. Age- and genderstandardized rates (/100 000/year in the population aged 30 years and older) for Finland, Croatia, Israel, Thailand, and Japan are 4.7, 5.6, 10.7, 7.0, and 11.4, respectively. These show a trend of increasing disease with more eastern location. ${ }^{27,28}$ The Israeli data are not in keeping with this pattern, although without more information on the biometric characteristics of people from this region, it is difficult to proffer an explanation. Similarly, a study from Minnesota, USA, reported an incidence of 8.3 in the population aged 40 and older. The cases were $89 \%$ northern European, $8 \%$ Asian, and 3\% black. Insufficient data are given to calculate a standardized rate..$^{29}$ None of these studies was prospective. Recently, there have been two studies in Singapore and Hong Kong that did prospectively study acute PAC in Chinese people, finding rates of 15.5 and 10.7..$^{27,30}$ Further research in Singapore used computerized hospital discharge data to compare the rate of angle closure in Chinese, Malay, and Indian people in Singapore. With figures of 12.2, 6.0, and 6.3 , it seems that Chinese people suffer at least twice as much symptomatic angle closure as do Southeast Asian people (Thai, Malay, Indonesian, and others). ${ }^{31}$ Chronic angle closure is currently not recognized as a common feature in European people, while among Asians it seems to be the predominant clinical manifestation. The implication of this is that the figures above for Asians probably represent only about a third of all angle closure. If we accept this, there does appear to be a considerable excess of angle closure in East Asians.

There have been few longitudinal studies of examining the rate of progression from angle-closure suspect status to established angle closure. One such study in Greenland found a 10-year incidence of angle closure in people with shallow anterior chambers of $16 \% .{ }^{32}$ Even higher rates have been reported in Southern India. Among the people with narrow drainage angles, 22\% (95\% CI: 9.8, 34.2) developed synechial $(64 \%)$ or appositional angle closure (36\%) over a period of 5 years. ${ }^{15}$ The people with established angle-closure at the time of the initial survey were advised to undergo laser iridotomy. Eight of 28 people with angle closure reexamined $(28 \%, 95 \%$ CI: 12,45$)$ had progressed to PACG over 5 years. One of nine who underwent LPI progressed compared to seven of 19 who refused LPI. ${ }^{14} \mathrm{~A}$ randomized, controlled trial is currently underway to assess the benefits of prophylactic treatment for angle closure in Asian people. ${ }^{33}$

\section{Anatomical and biometric risk factors}

A small eye with a shallow anterior chamber, short axial length, small corneal diameter and steep curvature, shallow limbal chamber depth, and a thick relatively anteriorly positioned lens are all considered risk factors for PAC. ${ }^{34-39}$ Anterior chamber depth (ACD) is widely regarded as the most easily measured index of risk of angle-closure. The majority of studies suggest an inverse relationship between prevalence of PAC and mean ACD in different populations. ${ }^{37,40-43}$ However, a study comparing ACD in Taiwanese Chinese and both White and Black residents of Baltimore did not find a significant difference in the biometric characteristics of these three groups using handheld ultrasound. The authors suggested that factors other than ACD, such as high rates of plateau iris configuration, might explain the propensity to PAC in Chinese people. ${ }^{44}$ This finding emphasizes that it is unlikely that a single risk factor will fully explain the inter-racial predisposition towards angle closure.

\section{Gonioscopy}

Gonioscopic examination remains the most important method of identifying signs of angle closure. Its successful usage is highly dependent on experience of the examiner. Several methods for grading the risk of angle closure have been devised. These include the Scheie, Shaffer, and Spaeth systems, which describe several characteristics of the drainage angle, including the proximity of the peripheral iris and trabecular meshwork on the basis of visibility of anatomical landmarks, or estimation of the angle width in degrees. ${ }^{45-47}$ These gonioscopic grades provide an index of the likelihood of closure. ${ }^{16} \mathrm{~A}$ dichotomous classification of drainage angle width (and perceived risk of closure) is used in epidemiological research. Angles have been termed 'occludable' or 'not occludable' based on the visibility of the posterior trabecular meshwork in the static gonioscopy. It is likely that the criteria used to make this distinction are unduly stringent, and exclude many cases of angle closure. Attempts have been made to remove some of the subjectivity from gonioscopy. The use of a graticule in the slit lamp eyepiece to measure the distance from iris insertion to Schwalbe's line, termed 'biometry gonioscopy,' has been suggested as a simple, accurate, and more reproducible method of gonioscopic examination..$^{48}$ Dynamic or indentation gonioscopy remains indispensable in differentiating synechial from appositional angle closure.

Comparing several studies, racial differences in gonioscopic findings are apparent. The percentages of eyes with Shaffer grade $\leqslant 2$ angle width was as low as $3.8 \%$ in the Framingham study (European people) ${ }^{49}$ and as high as $47.8 \%$ (8.5\% for grade 0 or 1 ) in Vietnamese clinic patients in the USA in the same age group. ${ }^{50}$ Shaffer grade 1 angles were present in 9\% Cape-Malay 
people in South Africa (of mixed African and Southeast Asian ancestry). ${ }^{51}$ Using identical definitions of an 'occludable' angle, our work in Mongolia and Singapore found occludable angles in 6.4 and $6.3 \%$, respectively. ${ }^{52}$

A hospital-based study comparing angle configuration in healthy East Asians, Afro-American, and Caucasians in the US, using the Spaeth gonioscopic grading scheme, gives another perspective. ${ }^{53}$ Iris insertion was found to be more anterior in Asian Americans compared with white and black subjects, although the recruited Asian individuals tended to be younger and more myopic. This characteristic was assumed to increase the risk of PAS formation in Asian eyes. In contrast, the results of a study using biometric gonioscopy found no significant difference in the mean exposed trabecular width between Singaporean Chinese, white, and black people in Baltimore after matching the age and sex. The Chinese people did, however, have deeper angles when young and significantly shallower angles in older age compared with black and white people, resulting in similar mean angle widths. There is growing evidence that Chinese populations in industrialized countries may be undergoing a pronounced change in ocular biometric characteristics, associated with higher rates of myopia in younger people, ${ }^{54,55}$ emphasizing that caution is required when drawing inferences regarding longitudinal trends from cross-sectional data.

\section{Mechanism of angle closure}

Pupil block is believed to be the major causative mechanism in most cases of angle closure in the West. Chandler $^{56}$ and Lowe ${ }^{57}$ suggested that pupil block is the consequence of contact between iris and anterior lens surface of the lens. In 1964, Lowe proposed a more sophisticated model of pupil block, describing a conceptual force vector onto the lens surface from resulting from co-contraction of both sphincter and dilator muscles. ${ }^{58}$ Using pharmacological provocation tests and anterior segment photographs, Mapstone refined this vector model of pupil-blocking force, proposing that it resulted from three forces-sphincter and dilator muscles, as well as iris elasticity, causing relative or absolute obstruction to aqueous flow. ${ }^{59}$ In eyes with PAC, the unique anatomical configuration (anterior location of the lens causing a shallow anterior chamber) decreases the angle between the respective vectors, increasing the resultant force onto the lens surface, and exacerbating relative pupil block. The pupil-blocking force then precipitates a resistance to aqueous flow from the posterior to anterior chamber. This then generates a pressure gradient across the iris, leading to anterior bowing.
However, the variable efficacy of iridotomy and the advent of UBM imaging have led to the realization that the pupil block hypothesis does not satisfactorily explain many cases of angle closure. The term 'plateau iris' is often (we believe incorrectly) used as an umbrella term for nonpupil-block angle closure. It is a term that describes both a particular configuration of the peripheral iris, and a clinical syndrome characterized by angle closure occurring in an eye with a patent iridotomy and plateau iris configuration. In European people, this configuration is usually caused by anteriorly rotated ciliary processes that push the peripheral iris forward, resulting in the characteristic angulation. The gonioscopic features of plateau iris were firstly described by Wand, ${ }^{60}$ with the underlying anatomical cause demonstrated by UBM imaging. ${ }^{61,62}$ Iridotomy alone is often ineffective in preventing angle closure in 'pure' plateau iris. The risk of closure depends on the height of the plateau and the width of the 'gutter' between the peripheral iris and trabecular meshwork (Figures 1a and b).

'Prominent last iris roll' is a term, sometimes attributed to Fuchs, used to describe an anterior, nonpupil-block entity. Eyes with this condition have a very thick iris which is peripherally thrown into prominent circumferential folds (Figure 1c), occupying a larger proportion of anterior chamber volume than a thin, blue iris. With dilation of the pupil, these folds become even more pronounced, and may come into contact with the trabecular meshwork. A recent review suggested that only $38 \%$ of angle closure in Chinese people is attributable solely to pupil block. Around $8 \%$ of cases are caused by nonpupil-block mechanisms alone, with the remaining $54 \%$ resulting from a combination of the two processes. ${ }^{63}$ Hung reported that the dark-prone provocation test was $60 \%$ positive ( arise of $8 \mathrm{~mm} \mathrm{Hg}$ or more) in $60 \%$ of Chinese eyes post-iridectomy, compared with $12.5 \%$ in normal eye. ${ }^{64}$ All were at a relatively early stage of synechial closure (eyes with more than $120^{\circ}$ of PAS were excluded). Such descriptions highlight the complexity of many cases of angle closure, where it is rare for one mechanism to solely responsible for closure.

External factors often seem to precipitate symptomatic angle closure. There appears to be a consistent association between angle closure and climatic conditions, although the precise conditions in which attacks occur vary. The general trend appears to be that extremes of temperature, possibly causing the population to remain indoors, may be the link. ${ }^{27,65-69}$ Anticholinergic agents benzhexol ${ }^{70}$ and ipratropium bromide ${ }^{71,72}$ are recognized as precipitating angle closure. Upper respirator tract infections and cold remedies may have the same effect. ${ }^{30,73}$ Posterior segment pathological processes $^{74}$ or therapeutic procedures ${ }^{75}$ occasionally cause a rise in IOP associated with transient angle 
closure. Idiosyncratic reactions to sulphonamide agents causing transient myopia, choroidal detachments, and profound shallowing of the anterior chamber are well
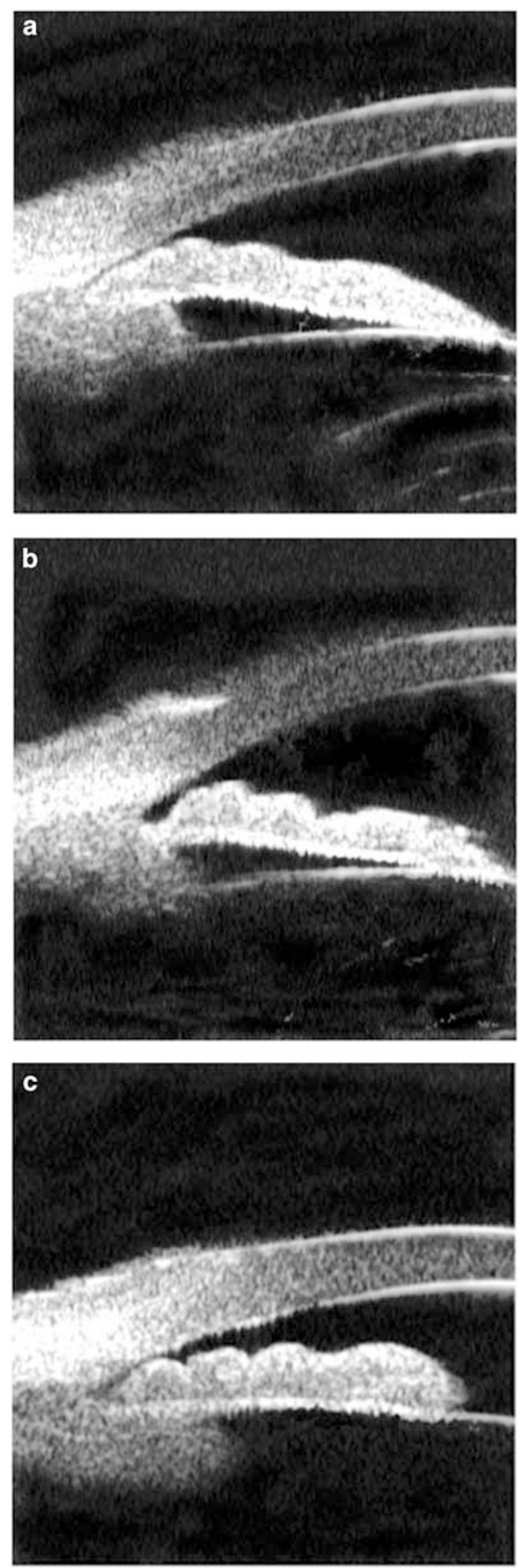

recognized as inducing 'acute' angle closure. ${ }^{76-78}$ This last observation has prompted Quigley to suggest a choroidal vascular mechanism in some cases of PAC. ${ }^{79}$ However, despite the increasing sophistication of our theoretical models of angle closure, we still do not fully understand the reason for closure in many cases.

\section{Effect of PI}

Laser iridotomy remains the cornerstone of management of angle closure, and results in a dramatic change in iris profile in cases with a pure pupil-block mechanism (Figures $2 \mathrm{a}$ and $\mathrm{b}$ ). It results in a significant increase in angle width in both Europeans and Asians with narrow angles. ${ }^{80,81}$ One study of predominantly Chinese people with narrow drainage angles found that PI produced a significant increase in angle width. It was also noted that the changes in iris morphology following PI were different occurring between normal and reduced illumination, suggesting an additional mechanism responsible for angle occlusion in the dark, independent of pupil block. ${ }^{81}$ The efficacy of PI for disease control is dependent both on the underlying mechanism causing closure, and the stage of the disease. Among people of African and Asian descent, greater extent of PAS, a higher presenting IOP, and a larger cup:disc ratio are all predictors of poor pressure control following iridotomy. ${ }^{17,18}$ Following an episode of symptomatic angle closure, reports suggest that satisfactory IOP control can be achieved in $42-72 \%$ of cases with PI alone. ${ }^{82,83}$ Once GON, defined as structural damage to the disc and a field defect, have developed, virtually all cases (94-100\%) will require further treatment to control IOP. ${ }^{84}$ Inferring that earlier intervention will definitely lead to a beneficial outcome in the long term is hindered by the phenomenon of 'lead-time bias' - the concept that earlier detection and treatment merely increase the

Figure 1 These ultrasound biomicrographs illustrate cases of angle closure without convexity of the posterior surface of the iris that accompanies pupil block. Note that the posterior surface of the iris is flat where not in contact with the ciliary body, suggesting the absence of a pressure gradient across the iris. Although considerable overlap exists, conceptually there are three distinct groups in Chinese eyes. (a) Shows typical plateau iris configuration with a pronounced angulation in the peripheral third of the iris caused by an anteriorly rotated ciliary body distorting the peripheral iris. (b) Has a bulky peripheral iris which angulates sharply to insert into the middle of the anterior surface of the ciliary body. There is no support from the apex of the ciliary body. (c) Has a similarly bulky peripheral iris. There is contact between the posterior surface of the iris and the ciliary body, although the apparent angulation is attributable to a prominent last iris roll. The iris inserts into the basal aspect of the anterior ciliary body. 

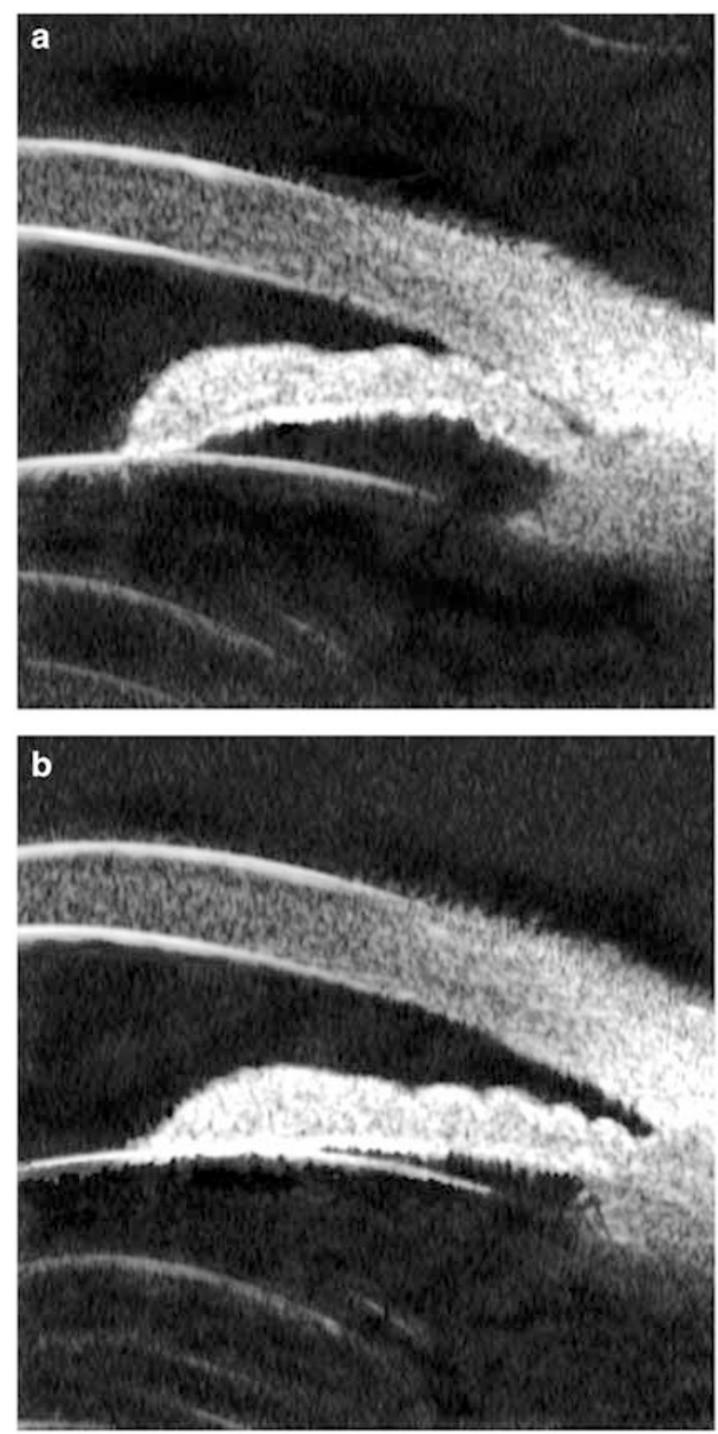

Figure 2 (a) and (b) are ultrasound biomicrographs illustrating the effect of peripheral laser iridotomy on pupil block. (a) Shows a pronounced angulation of the midperipheral iris and appositional contact around the level of Schwalbe's line. Note the aqueous-filled space (Mapstone's sinus) posterior to the area of contact between iris and trabecular meshwork. Such eyes may have apparently extensive closure, but normal or only mildly elevated IOP, as the bulk of the trabecular meshwork remains nonoccluded in the early stages of primary angle closure. Gonioscopic inspection of the iris configuration may suggest plateau iris. (b) Shows the same segment of the same eye following laser iridotomy. The angulation of the posterior surface of the mid-peripheral iris present in (a) without support from the ciliary body has completely resolved. This highlights the importance of laser iridotomy as the first step in management primary angle closure. The benefits can be difficult to predict, and in some cases are very pronounced.

period of followup, until the time when control of the disease is lost, with no change in outcome for the individual. However, the efficacy of prophylactic iridotomy or iridectomy in the fellow eye of one who has suffered 'acute' angle closure, in both Europeans and Asians (89-100\% control of IOP), ${ }^{33,82,85}$ is a persuasive argument that iridotomy, performed at an early stage in the disease process, does indeed have a beneficial effect.

Despite considerable research effort in the field of angle closure over the last decade, we still have many unanswered questions about the natural history and pathogenesis of the disease. The process of PAS formation is poorly understood. Similarly, we do not understand how, or indeed whether, appositional closure prior to formation of PAS affects trabecular meshwork function. The optimal management following PI remains to be investigated in an organized fashion, although paracentesis, lens extraction, and particularly iridoplasty may offer significant benefits over our previous management strategies. ${ }^{86-89} \mathrm{In}$ future treatment trials and the search for the definitive mechanism(s) of angle closure, the use of updated classification and outcome measures will almost certainly help. UBM and Scheimpflug image analysis have been major advances, permitting quantitative analysis of anterior segment anatomy. Anterior segment optical coherence tomography promises even greater biometric accuracy.

In summary, there are similarities in the characteristics of angle closure between Asians and Europeans. ACD appears to be a significant risk factor in both, and when there is advanced closure with GON, laser iridotomy alone will not control the disease. An important difference is that, among Asian people, the disease is typically asymptomatic. In addition, there is an increasing opinion that nonpupil-block mechanisms may account for a significant proportion of angle closure in Southern China. In view of our previous estimates that 1.7 million people in China are blind in both eyes from glaucoma, $91 \%$ due to angle closure ${ }^{89}$ there is a pressing need for data addressing the feasibility of screening for angle closure, and the benefit of prophylactic laser iridotomy in China.

\section{Acknowledgements}

Dr He is recipient of a UCL Graduate School Research Scholarship and a UCL Overseas Research Scholarship (2001061054). Professor Khaw receives support from the Medical Research Council (G9330070), Moorfields Special Trustees, and The Michael and Isle Katz Foundation.

\section{References}

1 Hu Z, Zhao ZL, Dong FT. An epidemiological investigation of glaucoma in Beijing and Shun-yi county (Chinese). Chung-Hua Yen Ko Tsa Chih (Chin J Ophthalmol) 1989; 25: 115-118. 
2 Congdon N, Wang F, Tielsch JM. Issues in the epidemiology and population-based screening of primary angle-closure glaucoma. Surv Ophthalmol 1992; 36: 411-423.

3 Foster PJ, Baasanhu J, Alsbirk PH, Munkhbayar D, Uranchimeg D, Johnson GJ. Glaucoma in Mongolia-a population-based survey in Hövsgöl Province, Northern Mongolia. Arch Ophthalmol 1996; 114: 1235-1241.

4 Congdon N, Quigley HA, Hung PT, Wang TH, Ho TC. Screening techniques for angle-closure glaucoma in rural Taiwan. Acta Ophthalmol 1996; 74: 113-119.

5 Wang N, Zhou W, Ye T, Wu Z, Liu H. Clinical studies of primary angle closure glaucoma (Chinese). Chung-Hua Yen Ko Tsa Chih (Chin J Ophthalmol) 1995; 31: 133-134.

6 Wong JS, Chew PT, Alsagoff Z, Poh K. Clinical course and outcome of primary acute angle-closure glaucoma in Singapore. Singapore Med J 1997; 38: 16-18.

7 Zhou WB. Stages of primary pupil-block chronic angleclosure glaucoma (Chinese). Chung-Hua Yen Ko Tsa Chih (Chin J Ophthalmol) 1993; 29: 114-116.

8 Lowe RF. Clinical types of angle-closure glaucoma. Aust NZ J Ophthalmol 1988; 16: 245-250.

9 Dhillon B, Chew PT, Lim ASM. Field loss in primary angleclosure glaucoma. Asia-Pac J Ophthalmol 1990; 2: 85-87.

10 Douglas GR, Drance SM, Schulzer M. The visual field and nerve head in angle-closure glaucoma. A comparison of the effects of acute and chronic angle closure. Arch Ophthalmol 1975; 93: 409-411.

11 Caprioli J, Gaasterland DE, Gross RL, Jampel H, Kolker AE, Lamping KA et al. Primary Angle-closure. Preferred Practice Patterns. San Francisco: American Academy of Ophthalmology, 2000.

12 South East Asia Gluacoma Interest Group. Asia Pacific Glaucoma Guidelines. Sydney: SEAGIG, 2003.

13 Foster PJ, Johnson GJ. Glaucoma in China: how big is the problem? Br J Ophthalmol 2001; 85: 1277-1282.

14 Thomas R, Parikh R, Muliyil J, Kumar R. Five-year risk of progression of primary angle closure to primary angle closure glaucoma: a population-based study. Acta Ophthalmol Scand 2003; 81: 480-485.

15 Thomas R, George R, Parikh R, Muliyil J, Jacob A. Five year risk of progression of primary angle closure suspects to primary angle closure: a population based study. $\mathrm{Br} \mathrm{J}$ Ophthalmol 2003; 87: 450-454.

16 Foster PJ, Nolan WP, Aung T, Machin D, Baasanhu J, Khaw PT et al. Defining 'occludable' angles in population surveys: drainage angle width, peripheral anterior synechiae and glaucomatous optic neuropathy in East Asian people. $\mathrm{Br} J$ Ophthalmol 2004; 88: 486-490.

17 Salmon JF. Long-term intraocular pressure control after $\mathrm{Nd}$ YAG laser iridotomy in chronic angle-closure glaucoma. J Glaucoma 1993; 2: 291-296.

18 Nolan WP, Foster PJ, Devereux JG, Uranchimeg D, Johnson GJ, Baasanhu J. YAG laser iridotomy treatment for primary angle-closure in east Asian eyes. Br J Ophthalmol 2000; 84: 1255-1259.

19 Ritch R, Lowe RF In: Ritch R, Shields MB, Krupin T (eds). The Glaucomas, 2nd edn. St Louis: Mosby, 1996 p 801.

20 Klein BE, Klein R, Sponsel WE, Frank T, Cantor LB, Martone $\mathrm{J}$ et al. Prevalence of Glaucoma. The Beaver Dam Eye Study. Ophthalmology 1992; 99: 1499-1504.

21 Wensor MD, McCarty CA, Stanislavsky YL, Livingston PM, Taylor HR. The prevalence of glaucoma in the Melbourne Visual Impariment Project. Ophthalmology 1998; 105: 733-739.
22 Hollows FC, Graham PA. Intraocular pressure, glaucoma and glaucoma suspects in a defined population. $\mathrm{Br} J$ Ophthalmol 1966; 50: 570-586.

23 Bonomi L, Marchini G, Marrafa M, Bernardi P, De Franco I, Perfetti $S$ et al. Epidemiology of angle-closure glaucoma. Prevalence, clinical types, and association with peripheral anterior chamber depth in the Egna-Neumarkt glaucoma study. Ophthalmology 2000; 107: 998-1003.

24 Zhao JL. An epidemiological survey of primary angleclosure glaucoma (PACG) in Tibet (Chinese). Chung-Hua Yen Ko Tsa Chih (Chin J Ophthalmol) 1990; 26: 47-50.

25 Shiose Y, Kitazawa Y, Tsukuhara S, Akamatsu T, Mizokami $\mathrm{K}$, Futa R et al. Epidemiology of glaucoma in Japan - a nationwide glaucoma survey. Jpn J Ophthalmol 1991; 35: 133-155.

26 Foster PJ, Oen FT, Machin DS, Ng TP, Devereux JG, Johnson GJ et al. The prevalence of glaucoma in Chinese residents of Singapore. A cross-sectional population survey in Tanjong Pagar district. Arch Ophthalmol 2000; 118: 1105-1111.

27 Seah SKL, Foster PJ, Chew PT, Jap A, Oen F, Fam HB et al. Incidence of Acute Primary Angle-closure Glaucoma in Singapore. An Island-Wide Survey. Arch Ophthalmol 1997; 115: $1436-1440$

28 Ivanisevic M, Erceg M, Smoljanovic A, Trosic Z. The incidence and seasonal variations of acute primary angleclosure glaucoma. Coll Antropol 2002; 26: 41-45.

29 Erie JC, Hodge DO, Gray DT. The incidence of primary angle-closure glaucoma in Olmstead County, Minnesota. Arch Ophthalmol 1997; 115: 177-181.

30 Lai JS, Liu DT, Tham CC, Li RT, Lam DS. Epidemiology of acute primary angle-closure glaucoma in the Hong Kong Chinese population: prospective study. Hong Kong Med J 2001; 7: 118-123.

31 Wong TY, Foster PJ, Seah SKL, Chew PTK. Rates of hospital admissions for primary angle closure glaucoma among Chinese, Malays, and Indians in Singapore. Br J Ophthalmol 2000; 84: 990-992.

32 Alsbirk PH. Anatomical risk factors in primary angleclosure glaucoma. A ten year follow up survey based on limbal and axial anterior chamber depths in a high risk population. Int Ophthalmol 1992; 16: 265-272.

33 Nolan WP, Baasanhu J, Undraa A, Uranchimeg D, Ganzorig S, Johnson GJ. Screening for primary angle closure in Mongolia: a randomised controlled trial to determine whether screening and prophylactic treatment will reduce the incidence of primary angle closure glaucoma in an east Asian population. Br J Ophthalmol 2003; 87: 271-274.

34 Lowe RF. A history of primary angle closure glaucoma. Surv Ophthalmol 1995; 40: 163-170.

35 Alsbirk PH. Anterior chamber depth in Greenland Eskimos. I. A population study of variation with age and sex. Acta Ophthalmol 1974; 52: 551-564.

36 Alsbirk PH. Corneal diameter in Greenland Eskimos. Anthropometric and genetic studies with special reference to primary angle-closure glaucoma. Acta Ophthalmol 1975; 53: 635-646.

37 Alsbirk PH. Limbal and axial chamber depth variations. A population study in Eskimos. Acta Ophthalmol 1986; 64: 593-600.

38 Lowe RF. Aetiology of the anatomical basis for primary angle-closure glaucoma. Biometrical comparisons between normal eyes and eyes with primary angle-closure glaucoma. Br J Ophthalmol 1970; 54: 161-169. 
39 Friedman DS, Gazzard G, Foster PJ, Devereux JG, Broman A, Quigley HA et al. Ultrasonographic biomicroscopy, Scheimpflug photography, and novel provocative tests in contralateral eyes of Chinese patients initially seen with acute angle closure. Arch Ophthalmol 2003; 121: 633-642.

40 Törnquist R. Shallow anterior chamber in acute angleclosure. A clinical and genetic study. Acta Ophthalmol 1953; 31(Suppl 39): 1-74.

41 Koenig SB. Myopic shift in refraction after penetrating keratoplasty with pediatric donor tissue. Am J Ophthalmol 1986; 101: 740-741.

42 Foster PJ, Alsbirk PH, Baasanhu J, Munkhbayar D, Uranchimeg D, Johnson GJ. Anterior chamber depth in Mongolians. Variation with age, sex and method of measurement. Am J Ophthalmol 1997; 124: 53-60.

43 Zhang SF. Estimation and clinical usefulness of anterior chamber depth in primary glaucoma (Chinese). Chung-Hua Yen Ko Tsa Chih (Chin J Ophthalmol) 1983; 19: 12-16.

44 Congdon NG, Qi Y, Quigley HA, Hung PT, Wang TH, Ho TC et al. Biometry and primary angle-closure glaucoma among Chinese, White and Black populations. Opthalmology 1997; 104: 1489-1495.

45 Scheie HG. Width and pigmentation of the angle of the anterior chamber. A system of grading by gonioscopy. Arch Ophthalmol 1957; 58: 510-512.

46 Becker B, Shaffer RN. Diagnosis and Therapy of the Glaucomas. St Louis: CV Mosby, 1965; 42-53.

47 Spaeth GL. The normal development of the human anterior chamber angle: a new system of descriptive grading. Trans Ophthalmol Soc UK 1971; 91: 709-739.

48 Congdon NG, Spaeth GL, Augsburger JJ, Klancnik Jr J, Patel K, Hunter DG. A proposed simple method for measurement in the anterior chamber angle: biometric gonioscopy. Ophthalmology 1999; 106: 2161-2167.

49 Leibowitz HM, Krueger DE, Maunder LR. The Framingham Eye Study Monograph. Surv Ophthalmol 1980; 24(Suppl): 335-610.

50 Nguyen N, Mora JS, Gaffney MM, Ma AS, Wong PS, Iwach AG et al. A high prevalence of occludable angles in a Vietnamese population. Ophthalmology 1996; 103: 1426-1431.

51 Salmon JF, Mermoud A, Ivey A, Swanevelder SA, Hoffman $M$. The prevalence of primary angle-closure glaucoma and open angle glaucoma in Mamre, Western Cape, South Africa. Arch Ophthalmol 1993; 111: 1263-1269.

52 Wong TY, Foster PJ, Hee J, Ng TP, Tielsch J, Chew SJ et al. Prevalence and risk factors for refractive errors in adult Chinese in Singapore. Invest Ophthalmol Vis Sci 2000; 41: 2486-2494.

53 Oh YG, Minelli S, Spaeth GL, Steinman WC. The anterior chamber angle is different in different racial groups: a gonioscopic study. Eye 1994; 8: 104-108.

54 Wong TY, Foster PJ, Ng TP, Tielsch JM, Johnson GJ, Seah SKL. Variations in ocular biometry in an adult Chinese population in Singapore: The Tanjong Pagar Survey. Invest Ophthalmol Vis Sci 2001; 42: 73-80.

55 Wickremasinghe S, Foster PJ, Uranchimeg D, Lee PS, Devereux JG, Alsbirk PH et al. Ocular biometry and refraction in Mongolian adults. Invest Ophthalmol Vis Sci 2004; 45: 776-783.

56 Chandler PA. Peripheral iridectomy. Arch Ophthalmol 1964; 72: 804.

57 Lowe RF. Angle-closure, pupil dilatation, and pupil block. Br J Ophthalmol 1966; 50: 385-389.
58 Lowe RF. Primary creeping angle closure glaucoma. $\mathrm{Br} \mathrm{J}$ Ophthalmol 1964; 48: 544-550.

59 Ritch R, Stegman Z, Liebmann J. Mapstone's hypothesis confirmed. Br J Ophthalmol 1995; 79: 300.

60 Wand M, Grant WM, Simmons RJ, Hutchinson BT. Plateau iris syndrome. Trans Am Acad Ophthalmol Otol 1977; 83: 122-130.

61 Ritch R. Plateau Iris is caused by abnormally positioned ciliary processes. J Glaucoma 1992; 1: 23-26.

62 Pavlin CJ, Ritch R, Foster FS. Ultrasound biomicroscopy in plateau iris syndrome. Am J Ophthalmol 1992; 113: 390-395.

63 Wang N, Wu H, Fan Z. Primary angle closure glaucoma in Chinese and Western populations. Chin Med J 2002; 115: 1706-1715.

64 Hung PT, Chou LH. Provocation and mechanism of angleclosure glaucoma after iridectomy. Arch Ophthalmol 1979; 97: 1862-1864.

65 Tupling MR, Junet EJ. Meteorological triggering of acute glaucoma attacks. Trans Ophthalmol Soc UK 1977; 97: 185-188.

66 Hillman JS, Turner JDC. Association between acute glaucoma and the weather and sunspot activity. $\mathrm{Br} \mathrm{J}$ Ophthalmol 1977; 61: 512-516.

67 David R, Tessler Z, Yassur Y. Epidemiology of acute angleclosure glaucoma: incidence and seasonal variations. Ophthalmologica 1985; 191: 4-7.

68 Gao F, Seah SKL, Foster PJ, Chia KS, Machin D. Angular regression and the detection of seasonal onset of disease. J Cancer Epidemiol Prevention 2002; 7: 29-35.

69 Bojic L, Vojnikovic B, Karelovic D, Jukic-Lesina T. Acute angle-closed glaucoma and meteorological factors in Split, Croatia. Coll Antropol 2001; 25: 105-109.

70 Friedman Z, Neumann E. Benzhexol-induced blindness in Parkinson's disease. BMJ 1972; 1: 605.

71 Humphreys DM. Acute angle closure glaucoma associated with nebulised ipratropium bromide and salbutamol. BMJ 1992; 304: 320.

72 Shah P, Dhurjon L, Metcalfe T, Gibson JM. Acute angle closure glaucoma associated with nebulised ipratropium bromide and salbutamol. BMJ 1992; 304: 40-41.

73 Khan MA, Watt LL, Hugkulstone CE. Bilateral acute angleclosure glaucoma after use of Fenox nasal drops. Eye 2002; 16: 662-663.

74 Hyams SW, Neumann E. Transient angle-closure glaucoma after retinal vein occlusion. Br J Ophthalmol 1972; 56: 353-355.

75 Blondeau P, Pavan PR, Phelps CD. Acute pressure elevation following panretinal photocoagulation. Arch Ophthalmol 1981; 99: 1239-1241.

76 Kronning E. Transient myopia following the use of acetazolamide. Acta Ophthalmol 1957; 35: 478-484.

77 Banta JT, Hoffman K, Budenz DL, Ceballos E, Greenfield DS. Presumed topiramate-induced bilateral acute angleclosure glaucoma. Am J Ophthalmol 2001; 132: 112-114.

78 Craig JE, Ong TJ, Louis DL, Wells JM. Mechanism of topiramate-induced acute-onset myopia and angle closure glaucoma. Am J Ophthalmol 2004; 137: 193-195.

79 Quigley HA, Friedman DS, Congdon NG. Possible mechanisms of primary angle-closure and malignant glaucoma. J Glaucoma 2003; 12: 167-180.

80 Marrafa M, Marchini G, Pagliarusco A, Perfetti S, Toscano A, Brunelli C et al. Ultrasound biomicroscopy and corneal endothelium in Nd:YAG-laser iridotomy. Ophthalmic Surg Lasers 1995; 26: 519-523. 
81 Gazzard G, Friedman DS, Devereux JG, Chew PT, Seah SK A prospective ultrasound biomicroscopy evaluation of changes in anterior segment morphology after laser iridotomy in Asian eyes. Ophthalmology 2003; 110: 630-638.

82 Playfair TJ, Watson PG. Management of acute primary angle-closure glaucoma: a long-term follow-up of the results of peripheral iridectomy used as an initial procedure. Br J Ophthalmol 1979; 63: 17-22.

83 Aung T, Ang LP, Chan SP, Chew PTK. Acute primary angleclosure: long-term intraocular pressure outcome in Asian eyes. Am J Ophthalmol 2001; 131: 7-12.

84 Rosman M, Aung T, Ang LP, Chew PT, Liebmann JM, Ritch R. Chronic angle-closure with glaucomatous damage: longterm clinical course in a North American population and comparison with an Asian population. Ophthalmology 2002; 109: 2227-2231.

85 Ang LP, Aung T, Chew PT. Acute primary angle closure in an Asian population: long-term outcome of the fellow eye after prophylactic laser peripheral iridotomy. Ophthalmology 2003; 107: 2092-2096.

86 Lam DS, Chua JKH, Tham CC, Lai JS. Efficacy and safety of immediate anterior chamber paracentesis in the treatment of acute primary angle-closure glaucoma. A pilot study. Ophthalmology 2002; 109: 64-70.

87 Jacobi PC, Dietlein TS, Luke C, Engels B, Krieglstein GK. Primary phacoemulsification and intraocular lens implantation for acute angle-closure glaucoma. Ophthalmology 2002; 109: 1579-1603.

88 Lam DS, Lai JS, Tham CC. Immediate argon laser peripheral iridoplasty as treatment for acute attack of primary angleclosure glaucoma: a preliminary study. Ophthalmology 1998; 105: 2231-2236.

89 Lam DS, Lai JS, Tham CC, Chua JK. Argon laser peripheral iridoplasty versus conventional systemic medical therapy in treatment of acute primary angle-closure glaucoma: a prospective, randomized, controlled trial. Ophthalmology 2002; 109: 1591-1596. 